\title{
Distribution of Tsc1 Protein Detected by Immunohistochemistry in Various Normal Rat Tissues and the Renal Carcinomas of Eker Rat: Detection of Limited Colocalization with Tsc1 and Tsc2 Gene Products In Vivo
}

\author{
Tomokazu Fukuda, Toshiyuki Kobayashi, Shuji Momose, Hideaki Yasui, and \\ Okio Hino
}

Department of Experimental Pathology, Cancer Institute, Tokyo, Japan

\begin{abstract}
SUMMARY: We and others previously demonstrated that hereditary mutation and a subsequent second hit in the rat homolog of tuberous sclerosis gene (Tsc2) are responsible for Eker renal carcinomas (RC). In humans, alteration in the TSC2 gene is known to cause the tuberous sclerosis complex (TSC) that results in hamartomatous lesions in multiple organs, but the function of TSC2 is not fully understood. In recent years, a second gene (TSC1) responsible for human TSC has been cloned, and binding between TSC1 and TSC2 proteins was reported. In this study, to clarify associations between Tsc proteins in vivo, the expression of Tsc1 protein was detected by immunohistochemistry, and compared with Tsc2 expression. Tsc1 protein was expressed in the nervous system and in many endocrine tissues, including pancreatic islets, the parathyroids, testis, and ovary. Tsc1 was also detected in the many epithelial tissues of organs, such as kidney, uterus, small and large intestine, and liver. Our results indicate overlapping, but not identical, organ distributions of Tsc1 and Tsc2 proteins. At the intracellular distribution, double fluorescent immunolabeling allowed the determination that only a partial portion of Tsc1 signals overlapped with Tsc2 in some organs. These results suggest the existence of co-localizing and independent forms of Tsc proteins in endogenous expressions. Additionally, relatively high expression of Tsc1 protein was detected in RC in the Tsc2 mutant (Eker) rat. (Lab Invest 2000, 80:1347-1359).
\end{abstract}

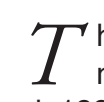
he Eker rat is well characterized as an animal model for dominantly inherited cancer (Hino et al, 1995). All of the Eker rats develop renal carcinomas $(\mathrm{RC})$ approximately 1 year after birth. According to Mendelian laws of inheritance, this occurrence suggests the existence of a single responsible gene (Hino et al, 1994). We and others have demonstrated that a germline mutation and a subsequent second hit in the rat tuberous sclerosis gene (Tsc2) are the responsible factor for the RC (Kobayashi et al, 1995; Xiao et al, 1995; Yeung et al, 1994). The anti-proliferative function and the second alteration in the earliest pathologic abnormalities of renal tubules (phenotypically altered tubules) indicate that Tsc2 is a tumor suppressor (Kobayashi et al, 1997; Kubo et al, 1995b; Orimoto et al, 1996). The Tsc2/TSC2 gene product is a large protein with a molecular weight of approximately 180

Received April 6, 2000.

This work was supported in part by a Grant-in-Aid for Cancer Research from the Ministry of Education, Science, Sports and Culture of Japan, the Organization for Pharmaceutical Safety and Research, and Naito Foundation.

Address reprint requests to: Dr. O. Hino, Department of Experimental Pathology, Cancer Institute, 1-37-1 Kami-ikebukuro, Toshima-ku, Tokyo 170-8455, Japan. Fax: 8135394 3815, E-mail: ohino@ims. u-tokyo.ac.jp kd (European chromosome 16 tuberous sclerosis consortium, 1993). Structural analysis has demonstrated the presence of a small region with weak homology to Rap1-GAP (Wienecke et al, 1995), or to putative src homology 3 binding region (Olsson et al, 1996) in TSC2. Binding to rabaptin 5, suggesting an association with endocytosis (Xiao et al, 1997) and a potential transcriptional activating effect (Tsuchiya et al, 1996) have been reported as possible functions of Tsc2/ TSC2. Additionally, an association with the cell cycle (Soucek et al, 1997) or steroid receptors (Henry et al, 1998 is possible. Although these results are informative, the actual functions of Tsc2/TSC2 in vivo and the pathogenesis of $\mathrm{RC}$ in Eker rat are not fully understood.

TSC2 is one of the genes responsible for the human tuberous sclerosis complex (TSC) that is a dominantly inherited syndrome associated with hamartomatous lesions in multiple organs. Recently, another gene (TSC1) responsible for human TSC was cloned (van Slegtenhorst et al, 1997). Although these two gene products do not show structural homology, nearly identical clinical phenotypes can be seen in patients affected by TSC1 and TSC2 mutations. Colocalization of TSC1 and TSC2 in hamartomatous tumors in the brain of a TSC patient (Johnson et al, 1999) and co-immunoprecipitation of TSC1 and TSC2 
(Plank et al, 1998) have been reported. Furthermore, direct binding of the two molecules was shown by yeast two-hybrid analysis (van Slegtenhorst et al, 1998), suggesting a cooperative function. This led us to question whether the interaction is conservative in all organs. In this study, chromogenic immunoreactivity of Tsc1 was examined and compared with previously reported Tsc2 expression patterns (Fukuda et al, 1999). Double immunofluorescence of Tsc1 and Tsc2 proteins in some organs was also examined to compare their localization in detail.

Although the expression of Tsc1 and Tsc2 in hamartomatous tumors (cortical tuber of brain or kidney angiomyolipoma) was reported (Johnson et al, 1999; Mizuguchi et al, 1996; Plank et al, 1999; Yeung et al, 1997), there is only limited information about the expression of TSC/Tsc proteins in other preneoplastic lesions in human and rodents. In rats, biallelic mutations of Tsc2 gene were detected in chemically induced rat RC (Satake et al, 1998). In human TSC, the major phenotype in kidney is angiomyolipoma, but not $\mathrm{RC}$. However, RC was reported in $2.2 \%$ of human TSC patients (Cook et al, 1996), and loss of heterozygosity (LOH) at TSC loci (9p34 and 16p13) in some TSCassociated RC was reported (Bjornsson et al, 1996). In this study, we also investigated the expression of Tsc1 protein in spontaneously developed RC of the Tsc2 mutant (Eker) rat.

\section{Results}

\section{Production and Specificity of Anti-Tsc1 Antibody}

For the detection of rat Tsc1 protein, we generated a rabbit polyclonal antibody ( $\alpha$-C-Tsc1) against 16 amino acid residues at the carboxyl terminus. The specificity of $\alpha$-C-Tsc 1 against human and rat tissues was first confirmed by western blotting (Fig. 1, A and B). Dominant signals were detected with the expected molecular weight (130 kd) (Fig. 1A, arrow). These bands disappeared with the addition of antigen pep-

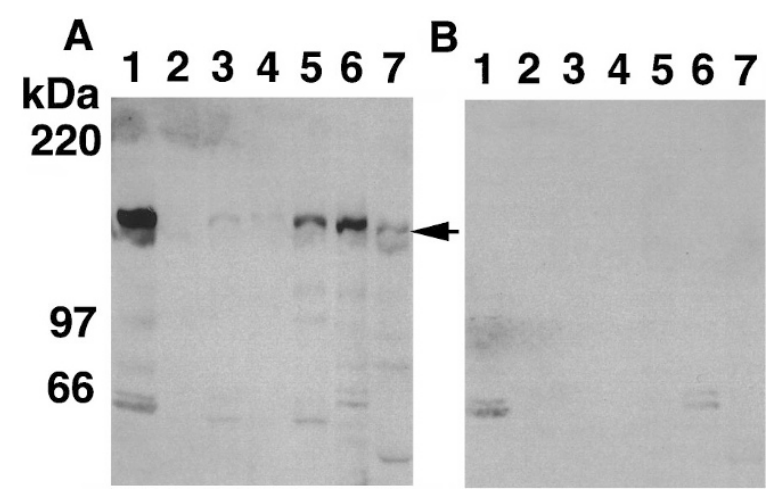

Figure 1.

Confirmation of the specificity of the $\alpha$-C-Tsc1 antibody by western blotting and immunohistochemistry. A, Western blot analysis with $\alpha$-C-Tsc1 and tissue proteins from brain (lane 1), heart (lane 2), mammary gland (lane 3), kidney (lane 4), ovary (lane 5), human brain (lane 6) and human kidney (lane 7). Tsc1 signals are indicated by the arrow. $B$, Western blot analysis with preadsorbed $\alpha$-C-Tsc1 antibody. Signals of Tsc1 at $130 \mathrm{kd}$ are no longer evident. Lanes are the same as in panel $A$. tide (Fig. 1B), confirming the specificity of $\alpha$-C-Tsc1. The signals detected in western blots were strongest in the brain (Fig. 1A). With immunohistochemistry, we confirmed reduced immunoreactivity in all organs with addition of antigen peptide to the primary antibody solution (representative results are shown in Fig. 5, C and D). From these data, we concluded that $\alpha$-C-Tsc1 gives specific binding to Tsc1 in western blotting and immunohistochemistry. For Tsc2, we used the rabbit polyclonal antibody to rat Tsc2, $\alpha$-pep1, which specifically recognizes 20 amino acids in exon 26, as previously reported (Fukuda et al, 1999).

\section{Overall Immunohistochemisty Results for Tsc1 Protein}

The distribution of the Tsc1 protein was examined in tissue sections of abdominal skin, adrenal glands, brain, eye balls, harderian glands, heart, kidney, large and small intestine, liver, lung, lymph nodes (mandibular), pancreas, parathyroid, pituitary gland, skeletal muscle, spleen, stomach, tongue, and urinary bladder. In these organs, there was no difference in Tsc1 expression between male and female rats. The ovary and uterus in females, and the prostate, seminal vesicles, epididymis, and testis of male rats were also examined. In all tissues, the Tsc1 protein was detected mainly in the cytoplasm, but also in the nuclei in some cases (see "Double Immunofluorescence for Tsc1 and Tsc2 Proteins"). Nuclear localization was confirmed by examination with a microscope before counterstaining (data not shown). The intensity of Tsc1 immunoreactivity was strongest in the nerve fibers of the nervous system, moderate with variation in epithelial tissues, and weak in connective and fat tissues. We compared our immunohistochemical results of Tsc1 with the previously described Tsc2 distribution (Fukuda et al, 1999).

\section{Distribution of the Tsc1 Protein in Tissues That Have Pathologic Abnormalities in the Eker Rat and in Human TSC Patients}

Virtually all Eker rats develop RC (Hino et al, 1993), and pituitary adenomas, hemangioma/hemangiosarcomas in spleen, and leiomyoma/leiomyosarcomas in uterus are also often observed (Kubo et al, 1994, 1995a). Thus, we examined the distribution of Tsc1 in these tissues. In the cortex of the kidney, Tsc1 protein was dominantly found in the distal renal tubules followed by the proximal tubules, but not in the glomerulus (Fig. 2A). In the uterus, endometrium and glands showed moderate immunoreactivity, and muscle fibers had faint immunoreactivity (Fig. 2B). In the pituitary, diffuse immunoreactivity was observed throughout the anterior and posterior lobes (Fig. 2C). The spleen was immunoreactive throughout the white and red pulp (Fig. 2D). Thus, the distribution of Tsc1 protein in the uterus and kidney was very similar to that of Tsc2 (Fukuda et al, 1999). In the spleen and pituitary, the immunoreactive tissues of Tsc1 overlapped with but were not identical with Tsc2 (Fukuda et al, 1999). 

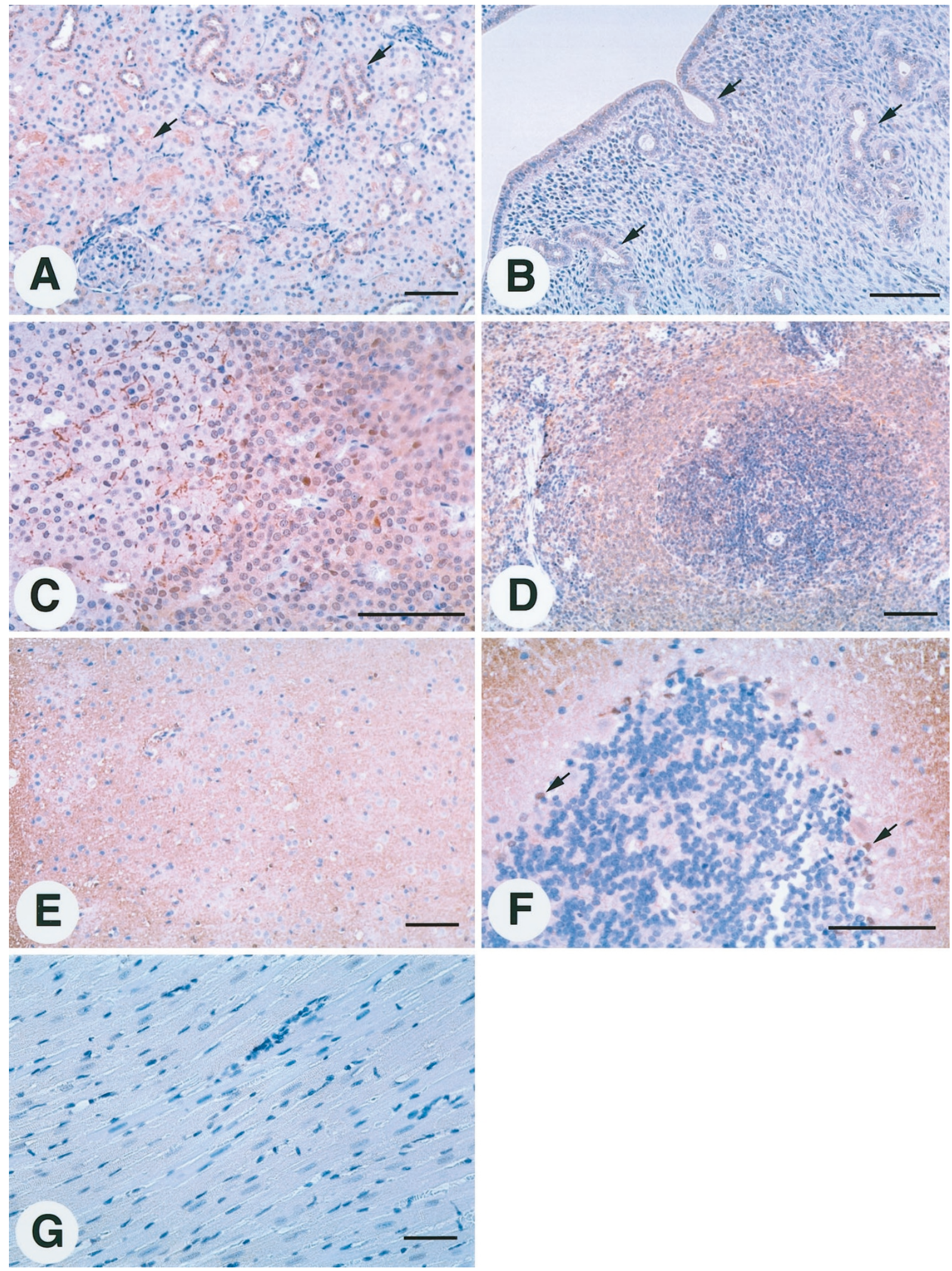

Figure 2.

Immunoreactivity of Tsc1 protein in different rat tissues. A, Solid immunoreactivity in distal tubules and weak immunoreactivity of proximal tubules in the cortex of the kidney (arrows). B, Endometrial epithelial cells and glands (arrows) had prominent immunoreactivity in the uterus. $C$ and $D$, Diffuse immunoreactivity in spleen $(C)$ and pituitary $(D)$. $E$ and $F$, Nerve fibers are strongly immunoreactive in the cerebral cortex $(E)$ and cerebellum $(F)$. Both neural and glial cells are immunoreactive. In the cerebellum, the nuclei of some unidentified cells are immunoreactive $(F$, arrows). $G$, Immunoreactivity of heart tissue. In all panels, sections were counterstained with hematoxylin. Scale bar, $100 \mu \mathrm{m}$. 
In human TSC, cortical tubers in the brain, angiomyolipomas in the kidney, rhabdomyomas in the heart, and lymphangiomyomatosis in the lung are often observed (Gomez, 1995). TSC-associated insulinoma has also been reported (Kim et al, 1995). Therefore, we investigated these organs in the rat with the Tsc1 antibody. In the cerebral cortex, there was intense immunoreactivity in nerve fibers. Lesser immunoreactivity was seen in cell bodies of neural and glial cells (Fig. 2E). The cerebellum had strong immunoreactivity in the molecular layer and weak immunoreactivity in the granular layer (Fig. 2F). The nuclei of some cells in the outer layer of the granular zone were immunoreactive, we suspected these might be basket cells from their distribution. Although Tsc2 protein was highly expressed in the heart, the Tsc1 antibody did not show high immunoreactivity in this tissue (Fig. 2G). Thus, the distribution of Tsc1 overlapped with Tsc2 in the brain, but was clearly different in the heart.

In the lung, the bronchus epithelial cells, dust cells, and type II epithelial cells were immunoreactive for Tsc1. Additionally, some, but not all, blood vessels were immunoreactive (Fig. 3A). Those more distant from the bronchus had stronger immunoreactivity. Elastica van Gieson (EVG) staining of semi-serial sections (Fig. 3, B and D) demonstrated that blood vessels containing elastic fibers only in the inner layer were immunoreactive whereas those with elastic fi- bers throughout their walls were not. Thus, veins, but not arteries, were immunoreactive. Furthermore, the immunoreactive tissue in lung veins showed yellow ocher staining on EVG staining (Fig. 3D). From the staining on EVG and hematoxylin and eosin stained sections (data not shown), the immunoreactive tissue in the lung vein seemed to be smooth muscle. The distribution of Tsc1 protein in the lung perfectly matched with that of Tsc2 (Fukuda et al, 1999).

In the pancreas, prominent immunoreactivity in pancreatic islets was found (Fig. 4, B, E, and H). We observed that strongly immunoreactive cells were surrounded with weakly immunoreactive cells in pancreatic islets (Fig. 4B). Double immunohistochemistry with insulin, glucagon, and somatostatin antibodies was performed to identify the positive cell types. The results indicated that the insulin positive $B$ cells strongly express the Tsc1 protein (Fig. 4, A to C) and $D$ and $B$ cells that are positive for somatostatin and glucagon express Tsc1 to a lesser extent (Fig. 4, D to I). Because the expression of the Tsc2 protein was reported to be limited in $B$ cells in pancreatic islets (Fukuda et al, 1999), we concluded that only B cells express both Tsc1 and Tsc2.

\section{Distribution in Other Tissues}

The epithelial cells in the mammary gland showed strong immunoreactivity for Tsc1 and Tsc2 (data not
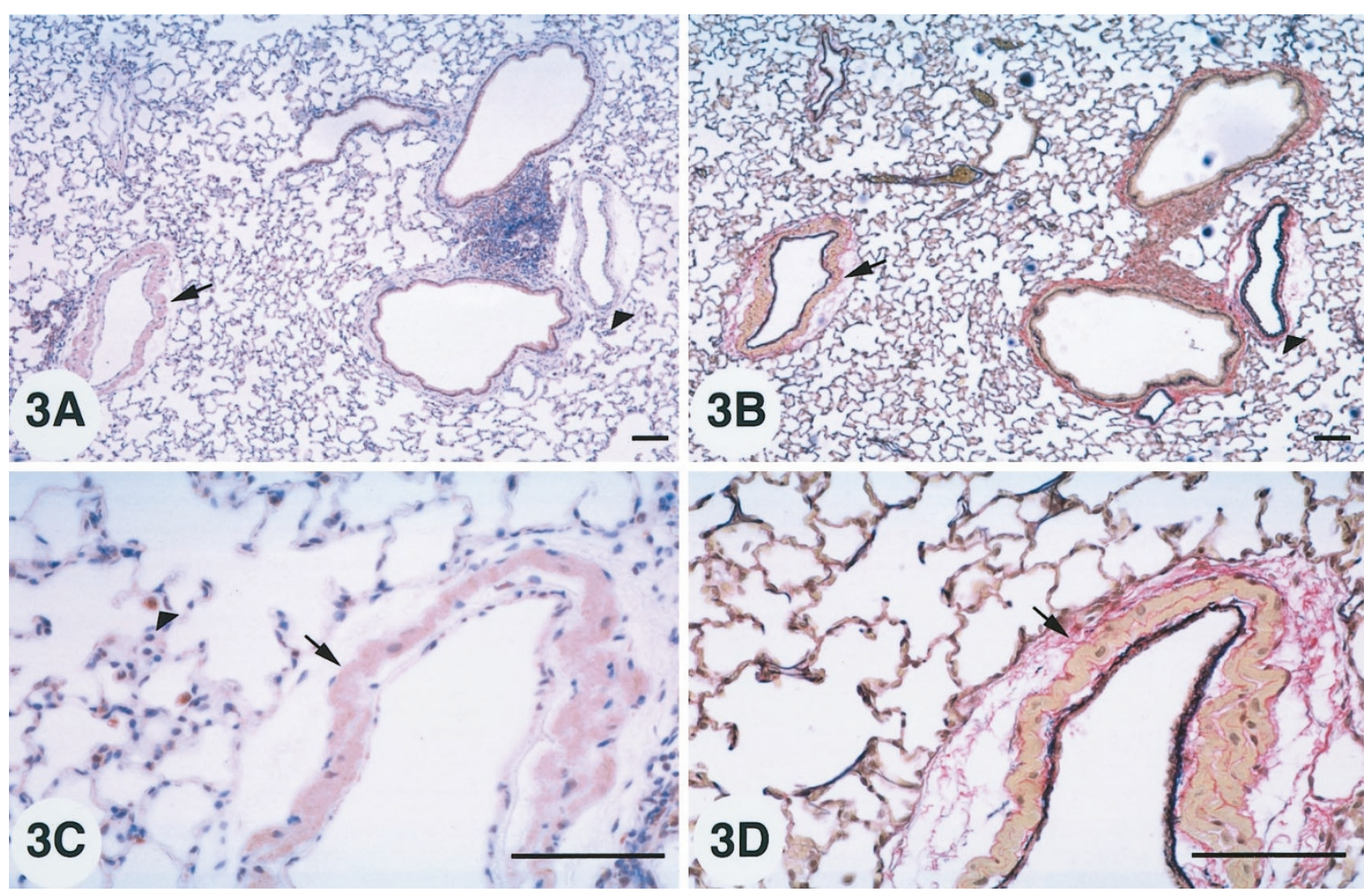

\section{Figure 3.}

Immunoreactivity for Tsc1 protein and Elastica van Gieson staining (EVG) in a semi-serial section of rat lung. $A$, Tsc1 immunoreactivity. The positive vessel (arrow) is more distant from the bronchus than the nonreactive vessel (arrowhead). Bronchus epithelial cells are also immunoreactive. $B$, EVG staining. The vein containing elastic fiber only in the inner layer (arrow) is indicated. The artery containing fibers throughout the vessel wall is indicated by the arrowhead. $C$ and $D$, High magnification of panels $A$ and $B$. The immunoreactive tissue (arrow) with Tsc1 is stained yellow in EVG ( $D$, arrow). Alveolar macrophages or Type II epithelial cells are also stained (C, arrowhead). Scale bar, $100 \mu \mathrm{m}$. 

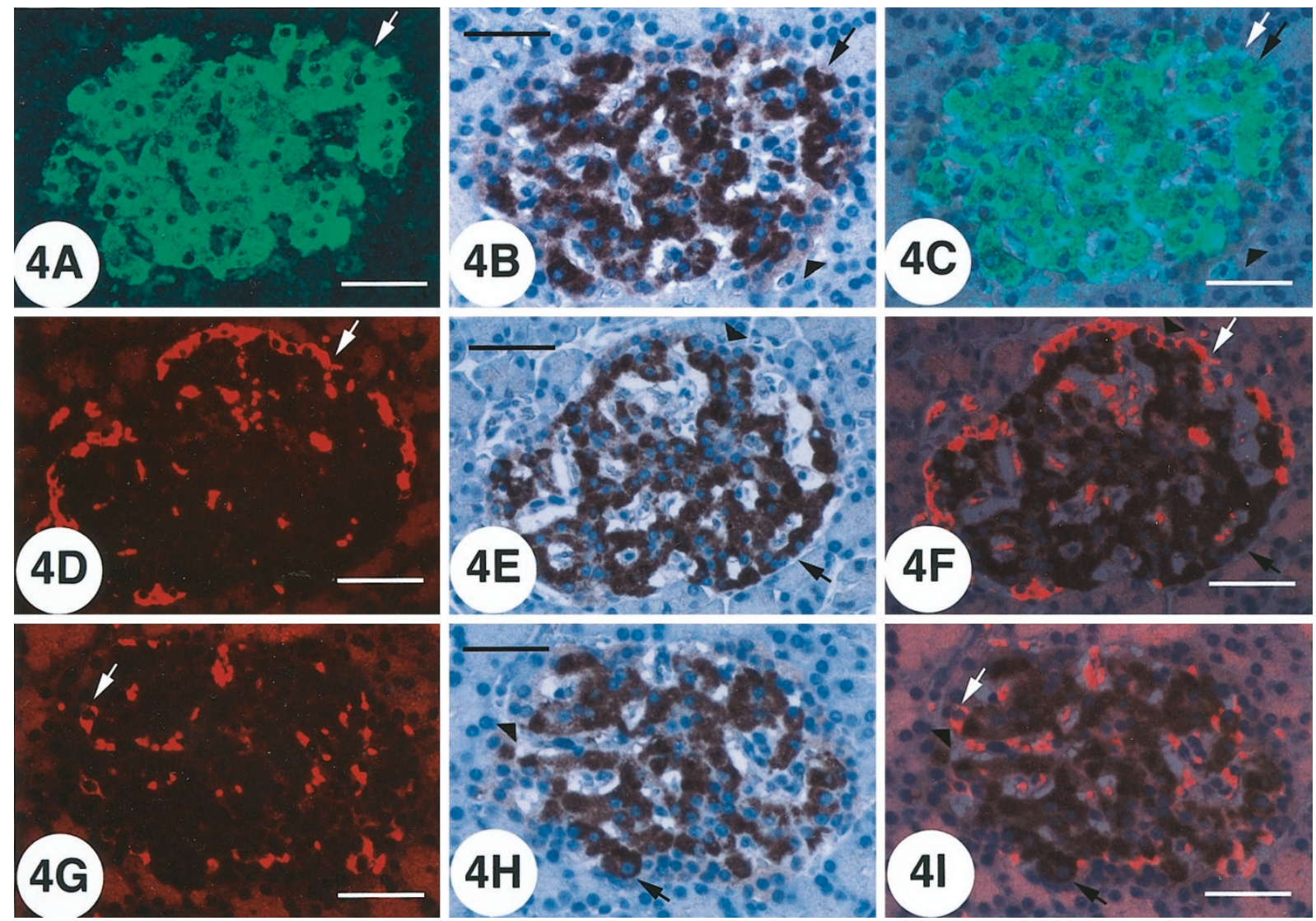

\section{Figure 4.}

Identification of Tsc1 immunoreactive cells in a pancreatic islet. $A, D$, and $G$, Fluorescent immunoreactivity of insulin $(A)$, glucagon $(D)$, and somatostatin $(G)$. White arrows (in $A, D$, and $G$ ) in each panel indicate immunoreactive cells. $B$, $E$, and $H$, Immunoreactivity for Tsc1. The arrows indicate strongly immunoreactive cells. The arrowheads show weakly immunoreactive cells. $C, F$, and $I$, Double-exposed images of Tsc1 and insulin $(C)$, glucagon $(F)$, and somatostatin $(I)$. There is good agreement between strong Tsc1 immunoreactivity and insulin $(C$, white arrow and black arrow). Cells immunoreactive for glucagon or somatostatin show weak immunoreactivity for Tsc1 ( $F$ and $I$, white arrow and arrowhead). Scale bar, $50 \mu \mathrm{m}$.

shown), and the interlobular, excretory, and granulated ducts of the salivary gland had moderate Tsc1 immunoreactivity (Fig. 5C) similar to that reported for Tsc2 (Fukuda et al, 1999). In the small and large intestine and gastric proper glands, absorptive epithelial tissues showed weak immunoreactivity similar to Tsc2 expression (Fig. 5B). Nerve fibers in the muscle layers were intensely immunoreactive for Tsc1 (Fig. $5 \mathrm{~B}$, arrow), which was not observed for Tsc2. In testis, expression was found only in the cytoplasm of spermatogonia and in primary spermatocytes (zygotene or pachytene phase) where nuclei had a rough pattern by hematoxylin staining (Fig. 5A). However, after the maturation division in spermatogenesis, spermatids and secondary spermatocytes had strong nuclear immunoreactivity (Fig. 5A). Results for other organs, liver, retina, harderian glands, skeletal muscle, prostate, and seminal glands are summarized in Table 1. From these data, we concluded that the organ distribution of Tsc1 is similar, but not identical with the Tsc2 distribution.

\section{Double Immunofluorescence for Tsc1 and Tsc2 Proteins}

Representative organs were examined by double immunofluorescence with confocal microscopy to more precisely compare the expression and localization of Tsc1 and Tsc2. We detected the Tsc2 protein by green signals (Alexa 488) and the Tsc1 protein by red signals (Cy3) with an indirect method. We performed control experiments with pancreas tissue sections to confirm the specificity of the double immunofluorescence. The addition of Tsc1 antigen peptide to the first antibody solution adsorbed red signals, but had no effect on the green Tsc2 signals (Fig. 6A) and the Tsc2 antigen peptide completely blocked the green signals without influencing the red Tsc1 signals (Fig. 6B). Neither green nor red signals could be seen with both antigen peptides (Fig. 6C), confirming the specificity.

In pancreatic islets, the Tsc2 protein showed a dot pattern. Tsc1 protein was detected as larger dots that were more widely distributed (Fig. 6D). At high magnification, most of the immunoreactive spots for the two proteins were separated, with only partial overlap (yellow or orange in Fig. 7A). In pancreatic acinar tissues, Tsc2 protein was weakly immunoreactive in the cytoplasm whereas Tsc1 was immunoreactive in both cytoplasm and nuclei (Fig. 7B). In the salivary gland, the dot appearance of Tsc1 was seen in granulated glands that were diffusely immunoreactive for Tsc2 (Fig. 7C). In the cortex of the kidney, Tsc2 was 

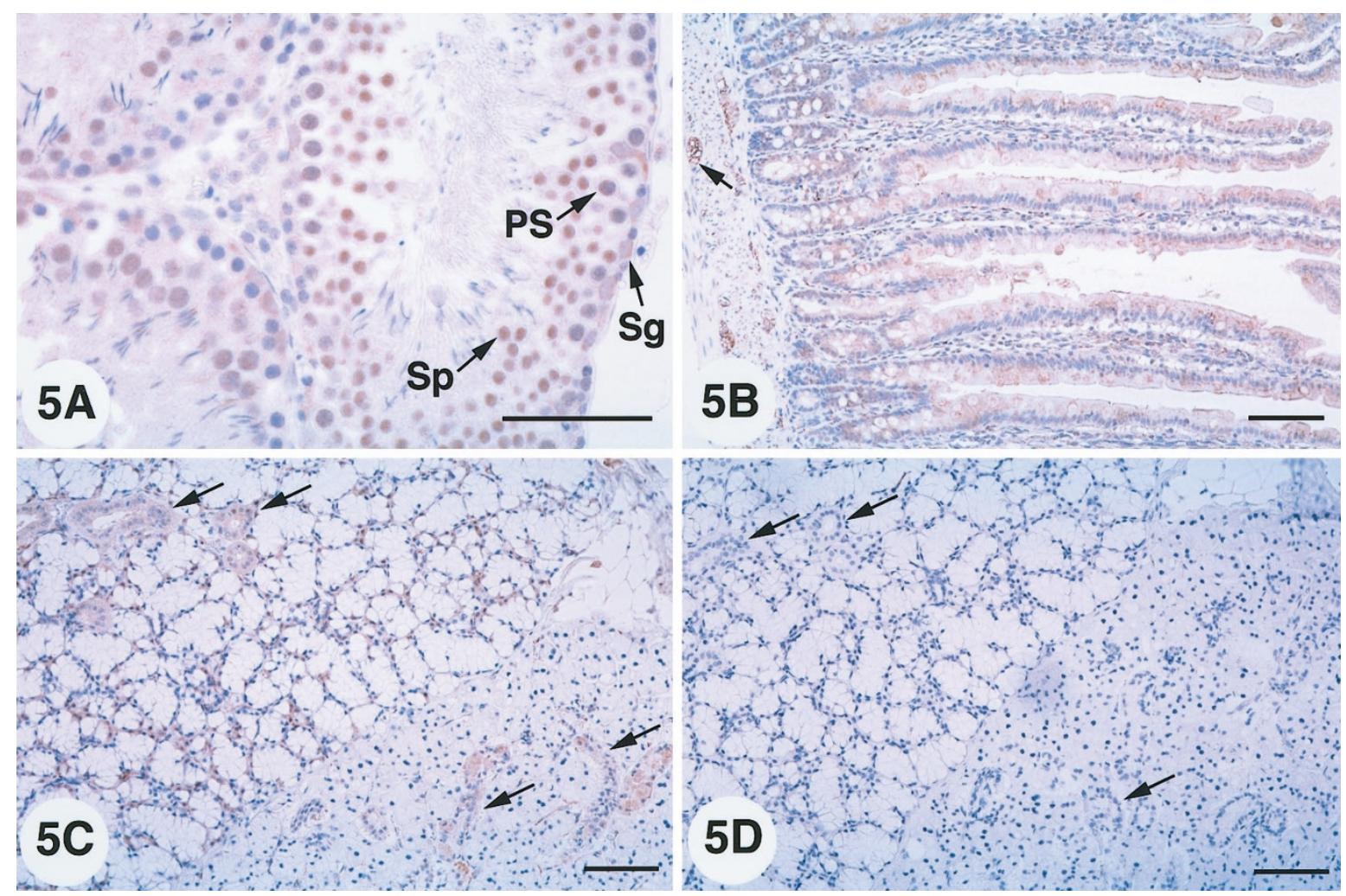

\section{Figure 5.}

Immunoreactivity of several rat tissues. $A$, Immunoreactivity of Tsc1 in rat testis. Spermatogonia $(S g)$, primary spermatocytes (PS), and spermatids and secondary spermatocytes $(S p)$ are indicated. Note that the subcellular localization of Tsc1 differs with the stage in the spermatogenesis. $B$, Epithelial cells and nerve fibers in the muscle layer (arrow) of the small intestine were immunoreactive for Tsc1. C, Immunoreactivity of a salivary gland with $\alpha$-C-Tsc1. Immunoreactive ducts and glands are indicated by arrows. $D$, Results for $\alpha$-C-Tsc1 preadsorbed with the specific peptide. Counterstaining with hematoxylin was performed. Scale bar, $100 \mu \mathrm{m}$.

detected throughout the renal proximal and distal tubules, whereas Tsc1 was detected as intense dots in distal tubules and weak immunoreactivity in proximal tubules (Fig. 7D). The immunoreactive dots of Tsc1 seemed to be intense in the apical phase of renal distal tubules. In the medulla of the kidney, the collecting tubules had a dotted pattern for both Tsc1 and Tsc2, but overlap was limited (Figure 7E).

The smooth muscle of the large intestine was weakly immunoreactive for Tsc1 and Tsc2 (Fig. 7F). In Tsc2 immunoreactivity, we observed faint lineal expression in the cytoplasm. Strong Tsc2 expression in cardiac myocytes was seen as parallel linear immunoreactivity along the myofibrils (Fig. 7G). Cell junctions of cardiac myocytes were observed as discontinuities of linear immunoreactivity (Fig. 7G). In the skeletal muscle, parallel linear or transverse immunoreactivity of muscle fibers was evident for Tsc2 (Fig. 7H). Tsc1 and Tsc2 expressions were dense in the cytoplasm surrounding nuclei in some portions of the skeletal muscle (data not shown). From these features, the Tsc2 protein seemed to be localized in the sarcoplasmic reticulum and/or myofibrils in the muscle (Carl et al, 1995). From the results obtained from fluorescent immunoreactivity, we concluded that the overlapping status of Tsc1 and Tsc2 protein differs in these organs.

\section{Detection of Complex Formation between Tsc1 and Tsc2 in Endogenous Expression by Immunoprecipitation}

To confirm the co-localization of Tsc1 and Tsc2 protein in endogenous expression, we performed an immunoprecipitation experiment. Because the endogenous expression levels of Tsc1 and Tsc2 in the kidney were not very high, and the antibody titers were not high for western blotting after immunoprecipitation, we detected the complex of Tsc1 and Tsc2 in cultured cell lines, PC12 (derived from a rat pheochromocytoma) and MCF7 (derived from a human mammary adenocarcinoma). MCF7 and PC12 cells have high expressions of Tsc1 and Tsc2 proteins (T Fukuda and O Hino, unpublished data; Vinters et al, 1999). We found coimmunoprecipitation of Tsc2 protein with the Tsc1 antibody (Fig. 8B). Briefly, Tsc2 protein was detected in immunoprecipitated proteins from MCF7 (Fig. 8B, lane 3) and PC12 (Fig. 8B, lane 5) using $\alpha$-C-Tsc1. Additionally, reduced signals were observed in the corresponding control proteins that were precipitated from the antigen-adsorbed antibody (Fig. 8B, lane 4 for MCF7, lane 6 for PC12), indicating the specificity of immunoprecipitation experiments. From these results, we concluded that Tsc1 formed a protein complex with Tsc2 in endogenous expression. 
Table 1. Summary of Chromogenic Immunostaining of Tsc1 Protein in Rat

\begin{tabular}{|c|c|}
\hline Organs & Tissues and cells demonstrating positive staining with Tsc1 antibodies \\
\hline Adrenals & Diffuse staining throughout the cortex and medulla \\
\hline Brain (cerebral cortex) & Diffuse staining throughout the neural and glial cells, nerve fiber \\
\hline Brain (cerebellum) & Diffuse staining throughout the molecular and granular layers \\
\hline Kidney & Staining in proximal and collecting tubules, strong staining in distal tubules \\
\hline Heart & Weak or faint staining in muscle fibers \\
\hline Lung & Bronchial epithelium, alveolar macrophages, smooth muscle of vein \\
\hline Liver & Positive staining for hepatocytes, negative for bile ducts and blood vessels \\
\hline Mammary glands & Ductal epithelial cells of mammary ducts \\
\hline Mandibular lymph node & Faint staining in cortex and cortical nodules \\
\hline Ovary & $\begin{array}{l}\text { Oocytes, follicular epithelial cells of stratum granulosum, ovarian cumulus, theca interna } \\
\text { and corpus luteum }\end{array}$ \\
\hline Pancreas & Strongly positive in B cell, positive for A and D cells \\
\hline Parathyroid & Chromophobic cells \\
\hline Pituitary & Diffuse staining throughout the anterior and posterior lobes \\
\hline Retina & Faint staining in layer of rods and cones, strong staining in the nerve fibers \\
\hline Salivary glands & Excretory ducts and glanular glands \\
\hline Seminal epididymis & Epithelial cells of epididymis and seminal ducts \\
\hline Skeletal muscle & Nerve fiber in muscle layer, weakly stained in muscle fibers \\
\hline $\begin{array}{l}\text { Small and large } \\
\text { intestine }\end{array}$ & Surface absorptive epithelial cells, intestinal glands, nerve fibers in muscle layer \\
\hline Spleen & Diffuse staining through white and red pulp \\
\hline Stomach & $\begin{array}{l}\text { Diffuse staining in gastric proper glands and strong staining of nerve fiber in muscle } \\
\text { layer }\end{array}$ \\
\hline Testis & Cytoplasms in spermatogonia and primary spermatocytes, the nuclei in spermatid \\
\hline Tongue, abdominal skin & Strong staining in nerve fibers and weak staining in muscle fibers \\
\hline Uterus & Endometrial epithelial cells and glands \\
\hline
\end{tabular}

\section{Double Immunofluorescence for Tsc1 and Tsc2 Proteins in Eker Preneoplastic Lesions and RC}

The causative steps for $\mathrm{RC}$ of Eker rat are the hereditary mutation and subsequent second hit in the rat Tsc2 gene. The inactivation of the Tsc2 protein might influence the expression of Tsc1, therefore we examined the expression of Tsc1 and Tsc2 proteins in spontaneously developed renal tumors from three animals by double immunofluorescence. Renal tumors were classified into four groups, positive for both Tsc1 and Tsc2 (Fig. 9A), negative for Tsc1 and positive for Tsc2 (Fig. 9C), negative for both Tsc1 and Tsc2 (Fig. 9D), or positive for Tsc1 and negative for Tsc2 (Fig. 9E). Sustained Tsc2 immunoreactivity in some Eker $\mathrm{RC}$ lesions has previously been reported, this might be explained by the inactivation pattern of wild type Tsc2 gene (eg, point mutation or LOH). At each neoplastic lesion, apparent reverse or direct correlation was not observed between Tsc1 and Tsc2 expression. However, a general tendency was observed for Tsc1 and Tsc2 immunoreactivity from the examination of 15 lesions including adenomas and carcinomas. For Tsc2 expression, 11 lesions showed faint or no immunoreactivity, and 4 showed intense or moderate immunoreactivity, suggesting low expression in the $\mathrm{RC}$ lesion. In the case of Tsc1, 10 lesions had strong immunoreactivity, and 5 were not immunoreactive. From these results, the Tsc1 protein seems to be highly expressed in Eker $\mathrm{RC}$ lesions. In spontaneous regenerative tu- bules, both Tsc1 and Tsc2 proteins were highly expressed (data not shown).

We performed western blotting of Tsc1 protein using five $\mathrm{RC}$ lesions and corresponding kidney tissues, to confirm the high expression of Tsc1 protein in spontaneous Eker RC. The results of five RC from three independent animals are given in Figure 8A. The expression of Tsc1 in RC was high compared with normal tissues, although no differences were detected with control antibody for $\beta$-actin.

\section{Discussion}

The present study demonstrated that the distribution of Tsc1 protein is identical with Tsc2 in the mammary gland, kidney, liver, lung, ovary, salivary gland, and uterus (Fukuda et al, 1999). In other organs such as the adrenals, brain, pituitary, small and large intestine, stomach, testis, and retina, the distributions of the two proteins overlapped, but were not identical. Tsc1 and Tsc2 are the genes responsible for human TSC and renal carcinogenesis in rodents (European chromosome 16 tuberous sclerosis consortium, 1993; Kobayashi et al, 1995, 1999; Onda et al, 1999; van Slegtenhorst et al, 1997), and binding between two proteins has been reported as the possible cooperative function (Plank et al, 1998; van Slegtenhorst et al, 1998). In terms of cell type specificity, the overlapped, but not identical expression profile between Tsc1 and Tsc2 suggest that Tsc1 protein does not always associate with Tsc2 in all organs and tissues. 

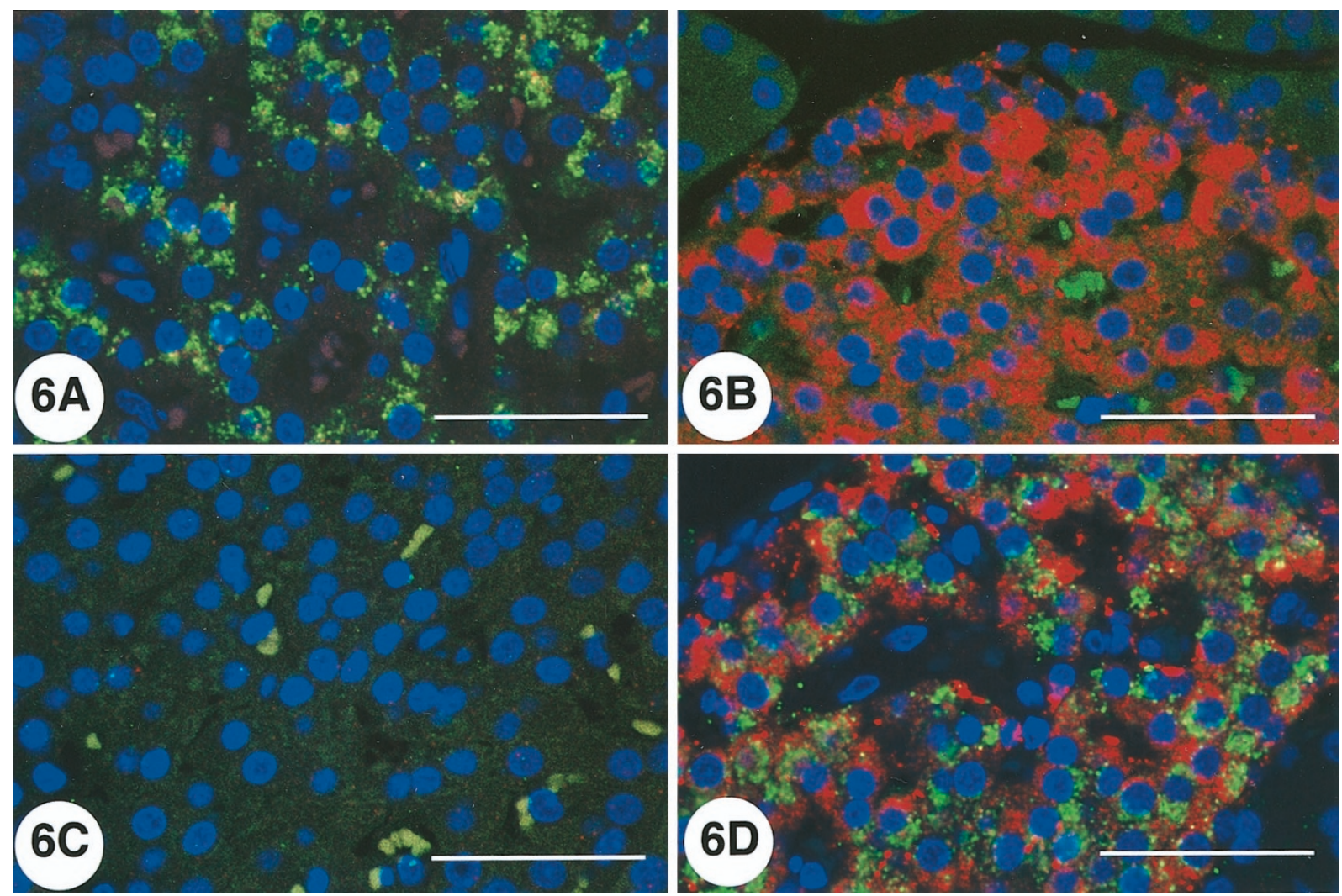

\section{Figure 6.}

Confirmation of the specificity of the double immunofluorescence for Tsc1 visualized with Cy3 (red), and Tsc2 visualized with Alexa 488 (green), in sections of a pancreatic islet. $A$, Immunoreactivity with Tsc1 antibody preadsorbed with its antigen peptide. Note the lack of effect on Tsc2 immunoreactivity (green), whereas almost no Tsc1 signals can be seen. B, Immunoreactivity with preadsorbed Tsc2 antibody. C, Immunoreactivity with both antibodies preadsorbed. No red or green signals. D, Double immunofluorescence for Tsc1 and Tsc2 proteins. Counterstaining with DAPI (blue) was performed for all panels. Scale bar, $100 \mu \mathrm{m}$.

At the subcellular level, we observed that the two proteins co-localized with each other to some extent, but localization was mostly independent in pancreatic islets, medulla of the kidney, and muscle fibers by double immunofluorescence. These results suggest the existence of co-localized and independent forms of Tsc1 and Tsc2 proteins in endogenous expression. We were able to immunoprecipitate the Tsc2 protein with Tsc1 protein in cultured cell lines. This indicates that Tsc1 can form a protein complex with Tsc2 in endogenous conditions, as reported with other cultured cell lines (Plank et al, 1998). Whereas the Tsc2 protein was reported to be localized to the Golgi apparatus (Wienecke et al, 1996), Tsc1 was detected in cytoplasmic vesicles under fluorescent microscopic examination (Plank et al, 1998). Although the subcellular distributions of two proteins were different, there is a possibility that the association of Tsc1 and Tsc2 might occur on the pathways of vesicular docking and membrane fusion, because a functional association of Tsc2 to endocytosis has been indicated (Xiao et al, 1997). Limited co-localization of Tsc1 and Tsc2 detected in our study might reflect a possible restricted association.

We detected some differences in organ distribution of Tsc1 between rat and human, compared with previously reported results in humans (Plank et al, 1999). Although rat testis had immunoreactivity, TSC1 expression in human testis is minimal (Plank et al, 1999). In contrast, minimal expression of Tsc1 was detected in rat heart, and high expression of TSC1 was reported in human heart (Plank et al, 1999). We found Tsc1 expression in rat testis with northern blotting, and confirmed the minimal expression of Tsc1 in rat heart with western blotting (data not shown and Fig. 1A). From these data, the difference of immunoreactivity in testis and heart might arise from the species-specificity among rat and human. In rat testis, we observed positive signals in the nuclei of spermatids and secondary spermatocytes, suggesting a change of localization during spermatogenesis. Additionally, nuclear localization of Tsc1 protein in pancreatic acinar tissues and some cells in the granular layer of cerebellum was observed, although with weak reactivity. The possible nucleus-associated function of Tsc1 remains to be determined.

Generally, Tsc1 was highly expressed in endocrineassociated tissues such as adrenals, mammary glands, ovary, pancreatic islets, and testis, as reported earlier for Tsc2 (Fukuda et al, 1999). In angiomyolipomas of kidney associated with tuberous sclerosis patients, high expression of the progesterone receptor has been reported (Henske et al, 1998; Logginidou et al, 2000). Furthermore, estrogen treatment enhances the RC of the Tsc2 mutant (Eker) rat (Wolf et al, 1998). These findings suggest that hormonal factors have 

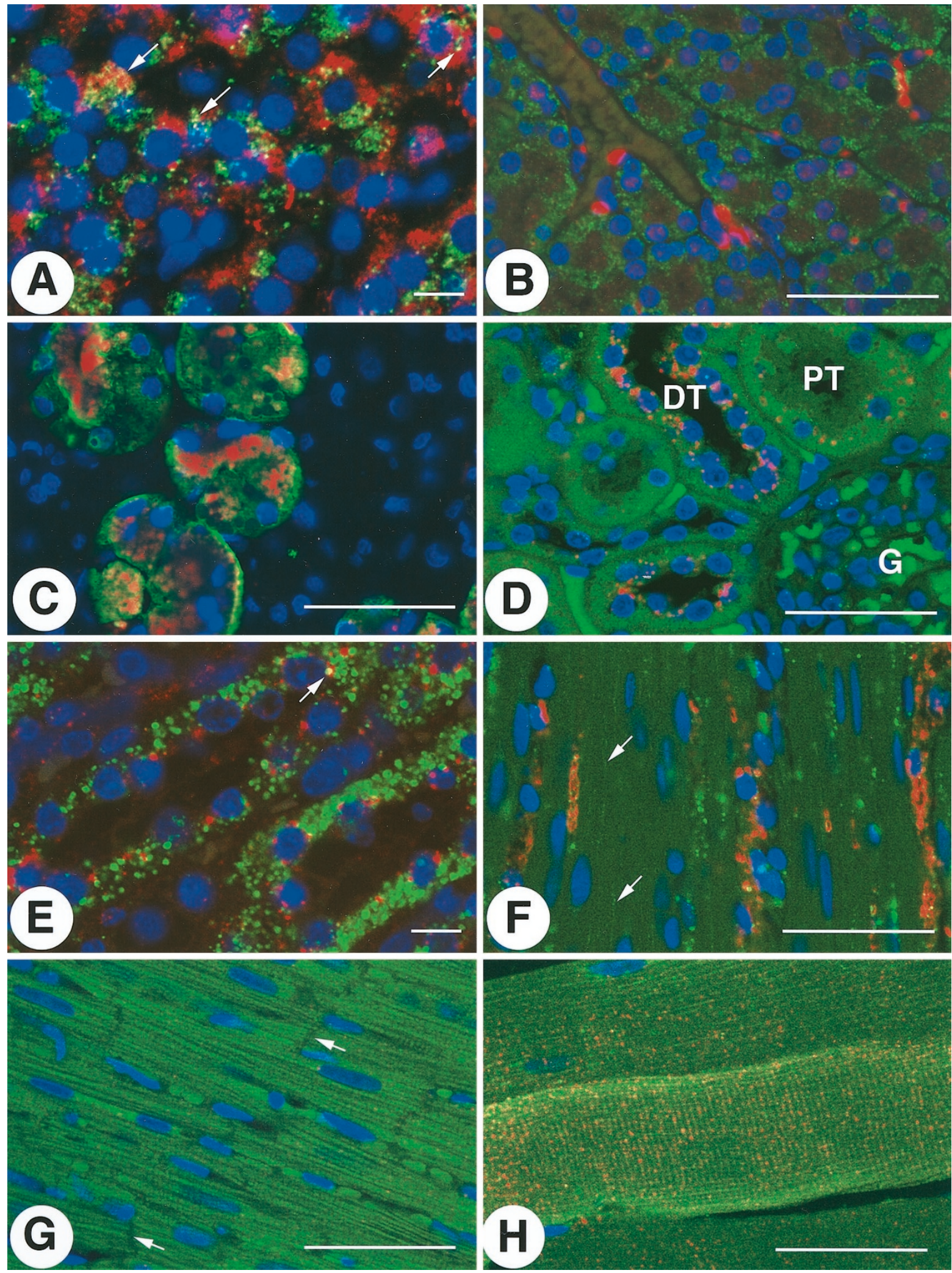

\section{Figure 7.}

Double immunofluorescence for Tsc1 and Tsc2 in various rat tissues. A, High magnification of a pancreatic islet, showing overlapping immunoreactive signals (arrows) detected as orange or yellow. B, Weak Tsc1 immunoreactivity in nuclei of pancreatic acinar tissue. C, Double immunoreactivity of salivary granular gland. Intense Tsc1 immunoreactivity is orange where it overlaps diffuse Tsc2 immunoreactivity. D, Immunoreactivity in cortex of kidney. Whereas the Tsc2 protein is diffusely detected throughout the renal tubules, Tsc1 shows dot-immunoreactivity mainly in the distal tubules. Proximal tubule $(P T)$, distal tubule $(D T)$, and glomerulus $(G)$ are indicated. $E$, Collecting tubules of kidney showed punctuate immunoreactivity for both Tsc1 and Tsc2. An overlapping signal is indicated by an arrow. $F, G$, and $H$, Immunoreactivity in smooth muscle of large intestine $(F)$, cardiac muscle $(G)$, and skeletal muscle $(H)$. Linear immunoreactivity in smooth muscle $(F$, arrows) and observed cell junctions in the heart are indicated (G, arrows). Scale bar $A$ and $E, 10 \mu \mathrm{m}$; others, $100 \mu \mathrm{m}$. 


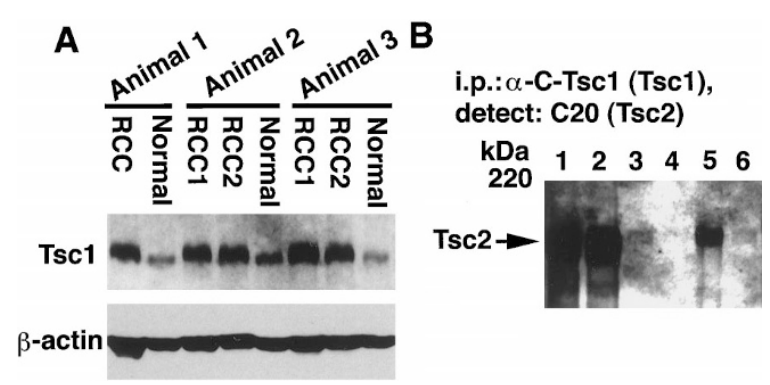

Figure 8.

Western blotting for Tsc1 in Eker RC and immunoprecipitation between Tsc1 and Tsc2. A, Western blotting of Tsc1 protein with Eker RC lesions from three animals. $B$, The immunoprecipitation of Tsc2 protein with Tsc1 antibody using proteins from PC12 and MCF7 cells. The whole protein from MCF7 cell (lane 1), whole protein from PC12 cell (lane 2), immunoprecipitated fraction with $\alpha$-C-Tsc1 antibody (lane 3 for MCF7, lane 5 for PC12), and immunoprecipitated fraction with antigen preadsorbed $\alpha$-C-Tsc1 antibody (lane 4 for MCF7, lane 6 for PC12) were blotted with the Tsc2 antibody. Dominantly precipitated Tsc2 protein can be seen in lanes 3 and 5 , and compared with the corresponding preadsorbed control (lanes 4 and 6).

some effect on pathogenesis of tuberous sclerosis and Eker RC.

Tsc1 protein was highly expressed in B cells and moderately expressed in $A$ and $D$ cells of rat pancreatic islets. For Tsc2, expression was limited to $B$ cells in pancreatic islets (Fukuda et al, 1999). Thus, our results indicate that only $B$ cells express both Tsc1 and Tsc2 proteins in rat pancreatic islets. Furthermore, muscles of lung veins were immunoreactive for Tsc1, but arteries were not. This distribution of Tsc1 protein in the lung matched Tsc2 (Fukuda et al, 1999). Although the development of insulinoma and pulmonary abnormalities have not been reported in Eker rat, co-expression of Tsc1 and Tsc2 in B cell and lung veins could affect development of TSC-linked insulinoma and lymphangiomyomatosis featuring immature smooth muscle cells (Gomez, 1995; Kim et al, 1995).

Tsc2 had linear immunoreactivity in cardiac and transverse immunoreactivity in smooth and skeletal muscle, suggesting a sarcoplasmic reticular and/or myofibrillary localization in muscle. Some abnormal myocardial cells in Tsc2 homozygous mutant rats or mice have been observed (Kobayashi et al, 1999; Pajak et al, 1997). Further investigation of the Tsc2 function in the muscle should facilitate an understanding of its role in the development of the muscle-related tumors such as cardiac rhabdomyomas and angiomyolipomas that are often observed in TSC patients.

In Eker RC lesions, Tsc2 expression was generally weak compared with normal tissues. However, some lesions showed intense immunoreactivity, as previously reported (Fukuda et al, 1999). However, Tsc1 was moderately expressed in RC lesions. Our data suggest that Tsc1 expression in RC may be influenced by the inactivation of Tsc2. Further investigations of the molecular relationships between Tsc1 and Tsc2 should help in understanding the pathogenesis of human TSC and Eker RC.

\section{Materials and Methods}

\section{Animals}

Female and male F344 rats were obtained at 12 weeks of age from Charles River Japan (Yokohama, Japan), and killed under ether anesthesia. Portions of tissues and organs were fixed in neutralized $10 \%$ buffered formalin for 48 hours and routinely processed for embedding in paraffin and sectioning at $3 \mu \mathrm{m}$. All animal experiments were performed according to $\mathrm{NIH}$ guidelines.

\section{Antibodies}

A rabbit antiserum against a synthetic peptide corresponding to 16 amino acid residues at the carboxyl terminal of rat Tsc1 was raised by repeated injection of carrier albumin-conjugated antigen with a cysteine residue at the amino terminal for coupling (CGQLHIMDYNETHHEHS). This anti-peptide antibody ( $\alpha-\mathrm{C}-$ Tsc1) was affinity-purified by passage through an affinity column coupled with antigen. The detailed method for $\alpha$-pep1 and its specificity were previously described (Fukuda et al, 1999).

\section{Chromogenic Immunoreactivity of Tsc1}

Tissue sections were dehydrated and heated in a microwave oven in citrate buffer for antigen retrieval. After blocking in 3\% hydrogen peroxide for 20 minutes, the sections were overlaid with $10 \%$ normal goat serum (NGS) in TBS. Sections were exposed to primary antibody (5 $\mu \mathrm{g} / \mathrm{ml}$ final concentration) in $10 \%$ NGS/TBS overnight at $4^{\circ} \mathrm{C}$. Sections were incubated with biotinylated goat anti-rabbit IgG (diluted 1:300) (DAKO, Glostrup, Denmark) in 10\% NGS/TBS for 2 hours at room temperature, then with streptavidin conjugated horseradish peroxidase (diluted 1:400) (DAKO). Binding was visualized with DAB (Sigma, St. Louis, Missouri) and hydrogen peroxide. After the hematoxylin counterstaining, sections were examined by microscope. Excess amounts of peptide antigens were added as negative controls. Stained signals were decreased with antibody adsorbance, confirming the specificity of the Tsc1 and Tsc2 antibody signals.

\section{Western Blotting Against Human and Rat Tissue Proteins}

To confirm the specificity of the Tsc 1 antibody ( $\alpha-\mathrm{C}$ Tsc1), we performed western blots with protein extracts of various organs from rats. Portions of rat tissues were homogenized in $1 \mathrm{x}$ sample buffer $(10 \%$ glycerol, 2.3\% SDS, 0.00625M Tris- $\mathrm{HCl}(\mathrm{pH} \mathrm{6.8),} \mathrm{5 \%}$ $\beta$-mercaptoethanol), electrophoresed in $6 \%$ polyacrylamide gels, and transferred to IPVH membranes (Millipore, Bedford, Massachusetts). The proteins from Eker RC lesions and its normal kidney tissues were also examined. The proteins from human brain and kidney were commercially obtained from Clontech (Clontech, Palo Alto, California). The membranes were exposed to the Tsc1 antibody, with or without prior adsorbance by antigen peptide. The immunologic 

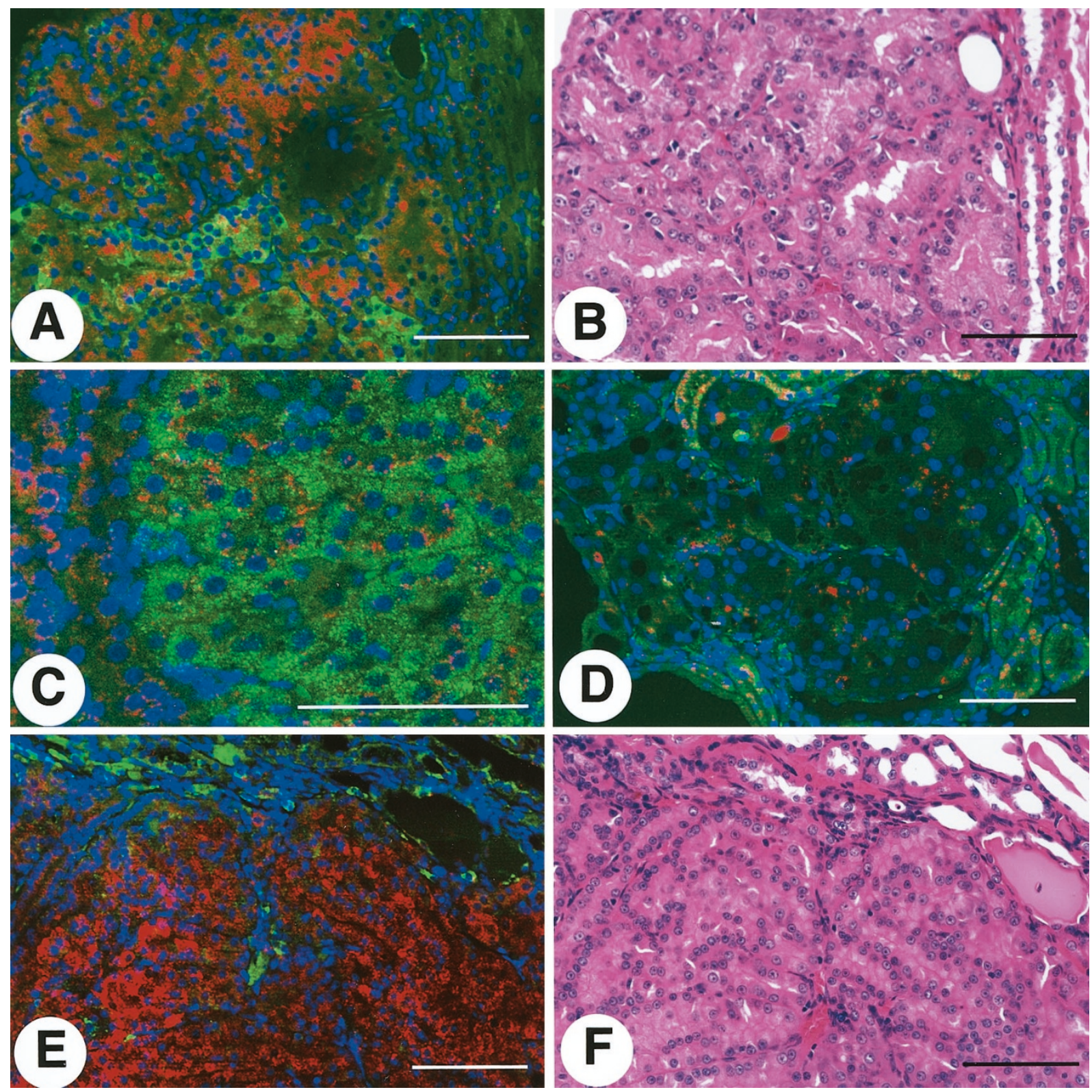

\section{Figure 9.}

Double immunoreactivity of Tsc1 and Tsc2 proteins in Eker renal adenomas and carcinomas. $A$ and $B$, Double immunofluorescence in an Eker RC $(A)$, and its morphology on hematoxylin and eosin staining (B). Immunoreactivity for both Tsc1 and Tsc2. C, An Eker RC immunonegative for Tsc1 and immunopositive for Tsc2. $D$, Adenoma show no immunoreactivity for either Tsc1 or Tsc2. $E$ and $F$, Double immunofluorescence in a carcinoma immunopositive for Tsc1 and immunonegative for Tsc2 $(E)$, and its hematoxylin and eosin appearance $(F)$. Scale bar, $100 \mu \mathrm{m}$.

reagent, Envision, for rabbit antibody (DAKO), was used as the secondary antibody at a 20 -fold dilution in PBS with $1 \%$ skim milk. Blocking and detection were performed as previously described (Fukuda et al, 1999).

\section{Immunoprecipitation Experiment}

For immunoprecipitation, PC12 and MCF7 cultured cells were dissolved in $1 \mathrm{x}$ lysis buffer $(10 \mathrm{~mm}$ Tris- $\mathrm{HCl}$ (pH 7.6), $50 \mathrm{~mm} \mathrm{NaCl}, 30 \mathrm{~mm} \mathrm{NaPPi}, 50 \mathrm{~mm}$ sodium fluoride, and $2 \%$ NP 40 ). $\alpha$-C-Tsc1 and protein A/G agarose (Life Technologies, Rockville, Maryland) were used for immunoprecipitation as previously described (Plank et al, 1998).

\section{Double Immunofluorescence for Tsc1 and Tsc2 Proteins}

Cell-type identification in pancreatic islets was performed as previously described (Fukuda et al, 1999). For the double immunofluorescence with Tsc1 and Tsc2, the $\alpha$-C-Tsc1 Tsc1 antibody and the $\alpha$-pep1 Tsc2 antibodies were used at the same concentrations given above. The double immunofluorescence method with microwave heating for two antibodies raised in the same species was that of Lan et al (1995). 
Because of the low titers of both antibodies in immunofluorescence, and to give resistance against the heating, the catalyzed signal amplification system (DAKO) was employed according to manufacturer's instructions. After incubation with the Tsc2 antibody ( $\alpha$-pep1), the Tsc2 protein was visualized with a HRPconjugated secondary antibody (DAKO), biotinylated Tyramide (DAKO) and Alexa 488-conjugated streptavidin (Molecular Probes, Eugene, Oregon). After microwave heating and hydrogen peroxide treatment, the Tsc1 antibody was exposed. The Tsc1 protein was detected with HRP-conjugated secondary antibody and Cy3-conjugated Tyramide (NEN, Boston, Massachusetts). Results were examined with phase contrast and confocal microscopy (Carl Zeiss, Thornwood, New York).

\section{Acknowledgements}

We thank Dr. H. Takeshima (Tokyo University, Tokyo, Japan) for expert advice and histopathologic judgments. We are also grateful to Dr. Y. Tani (DAKO JAPAN, Kyoto, Japan), Dr. H. Fukuda (National Institute for Environmental Studies, Tsukuba, Japan), and Dr. T. Umeda (Cancer Institute, Tokyo, Japan) for their technical support with double immunofluorescence and manuscript preparation. We also thank Drs. H. Sugano, T. Kitagawa (Cancer Institute, Tokyo, Japan), Y. Konishi (Nara Medical University, Nara, Japan), and A.G. Knudson (Fox Chase Cancer Center, Philadelphia, Pennsylvania) for their encouragement throughout this work.

\section{References}

Bjornsson J, Short MP, Kwiatkowski DJ, and Henske EP (1996). Tuberous sclerosis-associated renal cell carcinoma. Clinical, pathological, and genetic features. Am J Pathol 149:1201-1208.

Carl SL, Felix K, Caswell AH, Brandt NR, Ball WJ Jr, Vaghy PL, Meissner G, and Ferguson DG (1995). Immunolocalization of sarcolemmal dihydropyridine receptor and sarcoplasmic reticular triadin and ryanodine receptor in rabbit ventricle and atrium. J Cell Biol 129:672-682.

Cook JA, Oliver K, Mueller RF, and Sampson J (1996). A cross sectional study of renal involvement in tuberous sclerosis. J Med Genet 33:480-484.

European chromosome 16 tuberous sclerosis consortium (1993). Identification and characterization of the tuberous sclerosis gene on chromosome 16. The European Chromosome 16 Tuberous Sclerosis Consortium. Cell 75:1305-1315.

Fukuda T, Kobayashi T, Yasui $\mathrm{H}$, Tsutsumi M, Konishi $\mathrm{Y}$, and Hino O (1999). Distribution of Tsc2 protein in various normal rat tissues and renal tumours of Tsc2 mutant (Eker) rat detected by immunohistochemistry. Virchows Arch 434:341350.

Gomez MR (1995). History of the tuberous sclerosis complex. Brain Dev 17(Suppl):55-57.

Henry KW, Yuan X, Koszewski NJ, Onda H, Kwiatkowski DJ, and Noonan DJ (1998). Tuberous sclerosis gene 2 product modulates transcription mediated by steroid hormone receptor family members. J Biol Chem 273:20535-20539.
Henske EP, Ao X, Short MP, Greenberg R, Neumann HP, Kwiatkowski DJ, and Russo I (1998). Frequent progesterone receptor immunoreactivity in tuberous sclerosis- associated renal angiomyolipomas. Mod Pathol 11:665-668.

Hino O, Klein-Szanto AJ, Freed JJ, Testa JR, Brown DQ, Vilensky M, Yeung RS, Tartof KD, and Knudson AG (1993). Spontaneous and radiation-induced renal tumors in the Eker rat model of dominantly inherited cancer. Proc Natl Acad Sci U S A 90:327-331.

Hino O, Kobayashi E, Nishizawa M, Kubo Y, Kobayashi T, Hirayama Y, Takai S, Kikuchi Y, Tsuchiya H, Orimoto K, Kajino K, Takahara T, and Mitani H (1995). Renal carcinogenesis in the Eker rat. J Cancer Res Clin Oncol 121:602-605.

Hino O, Kobayashi T, Tsuchiya H, Kikuchi Y, Kobayashi E, Mitani H, and Hirayama $Y$ (1994). The predisposing gene of the Eker rat inherited cancer syndrome is tightly linked to the tuberous sclerosis (TSC2) gene. Biochem Biophys Res Commun 203:1302-1308.

Johnson MW, Emelin JK, Park SH, and Vinters HV (1999). Co-localization of TSC1 and TSC2 gene products in tubers of patients with tuberous sclerosis. Brain Pathol 9:45-54.

Kim H, Kerr A, and Morehouse H (1995). The association between tuberous sclerosis and insulinoma. Am J Neuroradiol 16:1543-1544.

Kobayashi T, Hirayama Y, Kobayashi E, Kubo Y, and Hino O (1995). A germline insertion in the tuberous sclerosis (Tsc2) gene gives rise to the Eker rat model of dominantly inherited cancer. Nat Genet 9:70-74.

Kobayashi T, Minowa O, Kuno J, Mitani H, Hino O, and Noda $T$ (1999). Renal carcinogenesis, hepatic hemangiomatosis, and embryonic lethality caused by a germ-line Tsc2 mutation in mice. Cancer Res 59:1206-1211.

Kobayashi T, Mitani H, Takahashi R, Hirabayashi M, Ueda M, Tamura H, and Hino O (1997). Transgenic rescue from embryonic lethality and renal carcinogenesis in the Eker rat model by introduction of a wild-type Tsc2 gene. Proc Natl Acad Sci U S A 94:3990-3993.

Kubo Y, Kikuchi Y, Mitani H, Kobayashi E, Kobayashi T, and Hino O (1995a). Allelic loss at the tuberous sclerosis (Tsc2) gene locus in spontaneous uterine leiomyosarcomas and pituitary adenomas in the Eker rat model. Jpn $\mathrm{J}$ Cancer Res 86:828-832.

Kubo Y, Klimek F, Kikuchi Y, Bannasch P, and Hino O (1995b). Early detection of Knudson's two-hits in preneoplastic renal cells of the Eker rat model by the laser microdissection procedure. Cancer Res 55:989-990.

Kubo Y, Mitani H, and Hino O (1994). Allelic loss at the predisposing gene locus in spontaneous and chemically induced renal cell carcinomas in the Eker rat. Cancer Res 54:2633-2635.

Lan HY, Mu W, Nikolic-Paterson DJ, and Atkins RC (1995). A novel, simple, reliable, and sensitive method for multiple immunoenzyme staining: Use of microwave oven heating to block antibody crossreactivity and retrieve antigens. J Histochem Cytochem 43:97-102.

Logginidou H, Ao X, Russo I, and Henske EP (2000). Frequent estrogen and progesterone receptor immunoreactivity in renal angiomyolipomas from women with pulmonary lymphangioleiomyomatosis. Chest 117:25-30. 
Mizuguchi M, Kato M, Yamanouchi $\mathrm{H}$, lkeda $\mathrm{K}$, and Takashima S (1996). Loss of tuberin from cerebral tissues with tuberous sclerosis and astrocytoma. Ann Neurol 40: 941-944.

Olsson PG, Schofield JN, Edwards YH, and Frischauf AM (1996). Expression and differential splicing of the mouse TSC2 homolog. Mamm Genome 7:212-215.

Onda H, Lueck A, Marks PW, Warren HB, and Kwiatkowski DJ (1999). Tsc2(+/-) mice develop tumors in multiple sites that express gelsolin and are influenced by genetic background. J Clin Invest 104:687-695.

Orimoto K, Tsuchiya H, Kobayashi T, Matsuda T, and Hino O (1996). Suppression of the neoplastic phenotype by replacement of the Tsc2 gene in Eker rat renal carcinoma cells. Biochem Biophys Res Commun 219:70-75.

Pajak L, Jin F, Xiao GH, Soonpaa MH, Field LJ, and Yeung RS (1997). Sustained cardiomyocyte DNA synthesis in whole embryo cultures lacking the TSC2 gene product. Am J Physiol 273:H1619-1627.

Plank TL, Logginidou H, Klein-Szanto A, and Henske EP (1999). The expression of hamartin, the product of the TSC1 gene, in normal human tissues and in TSC1- and TSC2linked angiomyolipomas. Mod Pathol 12:539-545.

Plank TL, Yeung RS, and Henske EP (1998). Hamartin, the product of the tuberous sclerosis 1 (TSC1) gene, interacts with tuberin and appears to be localized to cytoplasmic vesicles. Cancer Res 58:4766-4770.

Satake N, Urakami S, Hirayama Y, Izumi K, and Hino O (1998). Biallelic mutations of the Tsc2 gene in chemically induced rat renal cell carcinoma. Int J Cancer 77:895-900.

Soucek T, Pusch O, Wienecke R, DeClue JE, and Hengstschlager M (1997). Role of the tuberous sclerosis gene-2 product in cell cycle control. Loss of the tuberous sclerosis gene-2 induces quiescent cells to enter S phase. J Biol Chem 272:29301-29308.

Tsuchiya H, Orimoto K, Kobayashi K, and Hino O (1996). Presence of potent transcriptional activation domains in the predisposing tuberous sclerosis (Tsc2) gene product of the Eker rat model. Cancer Res 56:429-433.

van Slegtenhorst $M$, de Hoogt $R$, Hermans $C$, Nellist $M$, Janssen $B$, Verhoef $S$, Lindhout $D$, van den Ouweland $A$, Halley D, Young J, Burley M, Jeremiah S, Woodward K, Nahmias J, Fox M, Ekong R, Osborne J, Wolfe J, Povey S, Snell RG, Cheadle JP, Jones AC, Tachataki M, Ravine D, Sampson JR, Reeve MP, Richardson P, Wilmer F, Munro C, Hawkins TL, Sepp T, Ali JBM, Ward S, Green AJ, Yates JRW, Kwiatkowska J, Henske EP, Short MP, Haines JH, Jozwiak S, and Kwiatkowski DJ (1997). Identification of the tuberous sclerosis gene TSC1 on chromosome 9q34. Science 277: 805-808. van Slegtenhorst M, Nellist M, Nagelkerken B, Cheadle J, Snell R, van den Ouweland A, Reuser A, Sampson J, Halley D, and van der Sluijs P (1998). Interaction between hamartin and tuberin, the TSC1 and TSC2 gene products. Hum Mol Genet 7:1053-1057.

Vinters HV, Park SH, Johnson MW, Mischel PS, Catania M, and Kerfoot C (1999). Cortical dysplasia, genetic abnormalities and neurocutaneous syndromes. Dev Neurosci 21:248259.

Wienecke R, Konig A, and DeClue JE (1995). Identification of tuberin, the tuberous sclerosis-2 product. Tuberin possesses specific Rap1GAP activity. J Biol Chem 270:16409-16414.

Wienecke R, Maize JC Jr, Shoarinejad F, Vass WC, Reed J, Bonifacino JS, Resau JH, de Gunzburg J, Yeung RS, and DeClue JE (1996). Co-localization of the TSC2 product tuberin with its target Rap1 in the Golgi apparatus. Oncogene 13:913-923.

Wolf DC, Goldsworthy TL, Donner EM, Harden R, Fitzpatrick B, and Everitt JI (1998). Estrogen treatment enhances hereditary renal tumor development in Eker rats. Carcinogenesis 19:2043-2047.

Xiao GH, Jin F, and Yeung RS (1995). Germ-line Tsc2 mutation in a dominantly inherited cancer model defines a novel family of rat intracisternal-A particle elements. Oncogene 11:81-87.

Xiao GH, Shoarinejad F, Jin F, Golemis EA, and Yeung RS (1997). The tuberous sclerosis 2 gene product, tuberin, functions as a Rab5 GTPase activating protein (GAP) in modulating endocytosis. J Biol Chem 272:6097-6100.

Yeung RS, Katsetos CD, and Klein-Szanto A (1997). Subependymal astrocytic hamartomas in the Eker rat model of tuberous sclerosis. Am J Pathol 151:1477-1486.

Yeung RS, Xiao GH, Jin F, Lee WC, Testa JR, and Knudson AG (1994). Predisposition to renal carcinoma in the Eker rat is determined by germ-line mutation of the tuberous sclerosis 2 (TSC2) gene. Proc Natl Acad Sci U S A 91:11413-11416. 